DE91 015482

\title{
Wire Scanners for Beam Size and Emittance Measurements at the SLC*
}

\author{
M.C. Ross, J.T. Seeman, E. Bong, L. Hendrickson, D. McCormick, L. Sanchez-Chopitea \\ Stanford Linear Accelerator Center, \\ Stanford University, Stanford, Ca. 94309
}

\begin{abstract}
The SLC wire scanner beam profile monitors provide accurate beam size and emittance measurements for each bunth in the three bunch SLC beam. The beam size measurement crror for typical 50GeV SLC linac beams $(100 \mu \mathrm{m} \sigma(x, y))$ is better than $5 \mu \mathrm{m}$. Beam profile measurements can be performed throughout much of the SLC with no interruption to normal machine operation and no adverse impact on interaction region detector backgrounds. The linac input and output emittance is determined using sets of four scanners spaced by $-45^{\circ}$ betatron phase advance. Each scanner contains three wires, $x, y$ and $u$ (45"), from which an cstimate of the $x-y$ coupling can be obtained. Advanced high level control software allows the usc of wire scanner data in fecdback and beam optimization procedures. Non-invasive scans are performed almost continually and the results are logged so that long tern trends in emittance can be examined. In this paper we describe the design, construction, performance and uses of SLC wire scarners.
\end{abstract}

\section{INTRODUCTION}

Measurements of the beam size and associaled optical parameters are key to SLC. In the past progress has been slowed by our inability to measurc beam size accurately in a rapid, non-invasive manner.

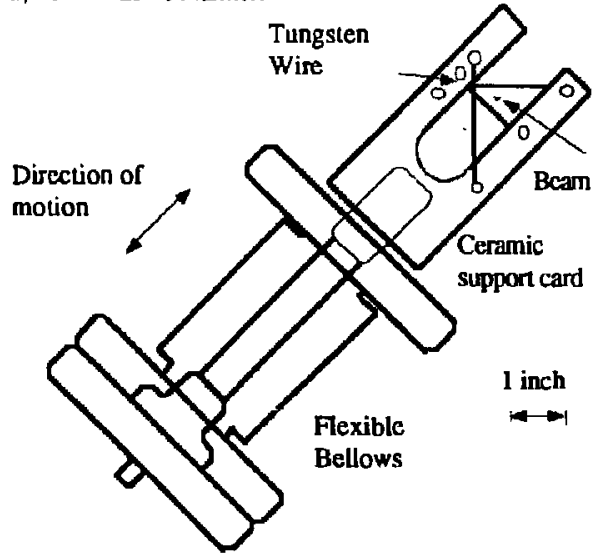

Figure 1: SLC wire scanner wire support card viewed in the beam direction. The translation stage and vacuum chamber are not shown.

*work supported by Department of Energy contract DE-AC03-76SF00515
In this paper we describe the design, construction, commissioning and ultimate uses of wire scanners in the SLC focusing on the linac and upstream systems scanners. Of particular interest is the interaction between the wire and the scattered radiation from the wire with the extreme electric field of the beam. As this field reaches the level of several volts/angstrom, as it does easily at the SL.C interaction point (and may in upstream pans of SLC), field cmission from the wire may occur.

A key featurc of SLC nperation is the degrec of high level active control required to keep it optimized. The high level of demand takes the instrument out of the category of a device primarily used for machine development or failure diagnosis purposes and elcvates it to an online device.

Fcedback requires a fast, non-invasive (or minimal impact) device which in turn means that the wire, not the beam, must be moved during the scan. The speed, range, vibration and other mechanical specifications can be generated from this requirenient and from the expected beam sizes and rates. Table 1 shows the expected performance of the scanners.

\section{MECHANICAL}

The mechanical design effort addressed the following problems: 1) wire and wire retention, 2) vibration over the large speed range and 3) positioning errors and position transducers. A particular concern was radiation damage.

A schematic diagram of the scanner is shown in figure 1. Several labs have built scanners of a similar design $1,2,2$. The wire is strung around $1.5 \mathrm{~mm}$ stainless steel studs set in a 3/16in thick alumina fork in such a way so that it can carry wires of three different orientations across the beam and provide $x, y$ and $u\left(45^{\prime}\right)$ scans. The carriage motion is actuated by a stepping motor through a $2 \mathrm{~mm}$ pitch ball screw, chosen because of the expected large number of cycles. Some difficulty was experienced obtaining the small pitch, high quality ball screw with no plastic parts. A $125 \mu \mathrm{m}$ thick stainless steel vacuum window opposite the wire allows low energy wide angle scatuered radiation to emerge from the vacuum chamber.

Both the cantilever nature of the wire support and the stepping motor contribute to wire vibration. We have used a piezo-electric accelerometer to quantify the motor related system vibration.

The wire chosen for the scanner was gold plated tungsten with a diameter of 0.3 obeam. The wire has an effective ' $\sigma$ ' of radius/2 which, when added in quadraturc to the bcam size, causes a $3 \%$ apparent increase when $\sigma_{\text {beam }}=$ wire diameter. Under nomal cenditions the wire size can be subtracted in quadrature from the measured size. 
At full SLC currents and rates, the beam can heal the wire substantially reaching a steady state temperature of $1000^{\circ} \mathrm{C}$. In the fast scan mode, the wire is subjected to continuous beam for no more than a few/seconds. However, the wire may be parked in the beam in error or for diagnoslic purposes and must be able to withstand continuous beam. By measuring the increase in resistance of the wire assembly an estimate of the wire temperature rise can be made. Resistance tests show good agrecment with a calculated rise of about $4^{\circ}$ C/pulse.

Table 1: Wire scanner performance specifications.

\begin{tabular}{|c|c|}
\hline Beam size resolution & $\langle 3 \% \sigma(=3.10 \mu \mathrm{m})$ \\
\hline Systematic error & $<3 \% \sigma \Leftrightarrow 3-10 \mu \mathrm{m})$ \\
\hline Emitlance (E) error & $10 \%$ (for $\left.\gamma \varepsilon=3 \times 10^{-5} \mathrm{~m} \cdot \mathrm{rad}\right)$ \\
\hline Dynamic range & $10^{9} \cdot 10^{11}$ particles/pulsc \\
\hline Vibration & Peak amplitude $\quad \leq 0.2 \sigma$ \\
\hline Relative positioning & $20 \mu \mathrm{m}$ \\
\hline Speed and acceleralion & $\begin{array}{l}1 \mathrm{~cm} / \mathrm{s} \max \\
0.3 \mathrm{~mm} / \mathrm{s} \mathrm{min} ; 0.2 \mathrm{~m} / \mathrm{s}^{2} \text { accel. }\end{array}$ \\
\hline Multibunch cperation & $\begin{array}{l}<5 \% \text { signal contamination from } \\
\text { nearby bunch ( } 60 \mathrm{~ns} \text { ) }\end{array}$ \\
\hline Radiation resistant & 10Mrad/year \\
\hline Lifetime & 100,000 cycles/year \\
\hline
\end{tabular}

As the wire is scanned through the beam its position is not encoded on each successive beam pulse, rather the current position of the wire is inferred from a check of the remaining step count. A position measurement using a radiation hard LVDT (linear differential transformer) is done at the limits of the scan to check that the expected position was reached.

\section{CONTROLS}

A scan consists of three steps: 1) move from PARK (near, but not in, any of the bearns) to the start of scan at maximum speed, 2) scan at the speed corresponding to the desired interpoint spacing and beam rate and 3) return to PARK at full speed. Only bricf pauses, to allow the device to comc to a completc stop, occur during the scan sequence. During muluwire emilunce nt skew scans, the wire moves to the next appropriate PARK. An important feature of this schenne is the use of machine wide data acquisition codes which coordinate the readback of the scanner step count and the signals from the wire scanner detcctor and therefore allow a great deal of flexibility in the choice of detector including, for example, the use of detectors several miles away.

Because the scanners are to be used for feedback, the application software that controls them must have sophisticated exception handling, error logging and status reporting. The control system software built around these devices allows use of the wire scanner at several levels. The lowest is the single scan and associated single pulse detector signal readout. This information allows checking the fit quality, scan ranges and other details. At the next level higher, the fit results can be used in the SLC control system correlation plot utility. ${ }^{4}$ This extremely powerful tonl, allowing the acquisition of scan data with other beam diagnostic data and machine parameters, has been invaluable for commissioning the scanners. All aspects of the gaussian fit to the scan data are available and are automatically acquired as an upstrcam device setting is controlled in a programmed way. Most automated optimization procedures are built around this facility. The next level of software does multiple scans and accumulates these results in the correlation plot utility. This includes four wire cmittance scan results and skew scan results. Finally, fecdback can perform the scans as a background task and implement the desired corrertions.

\section{SIGNAL DETECTOR}

The purpose of the wire signal detector is to indicate the amount of charge striking the wire. Secondary emission and forward scattering, used in many wire scanner systems, are often not practical at the SLC, the first because of problems discussed below and the second because of the very different beam line areas in which these devices have to operate. The most difficult region is just upstream of a high power collimator systcm. Radiation scattered by the wire in the forward direction is completely overwhelmed by the scattering from the collimator jaws thus making the use of small angle scaltered radiation impossible.

When the SLC interaction poirt (IP) wirc scanners ${ }^{5}$ werc first tested it was found that the secondary emission signal would increase dramatically when either the beam intensity exceeded about $5 \times 10^{9}$ or the $\sigma_{\text {beam }}<10 \mu \mathrm{m}$. The onset of this dramatic inerease is indicated by a very unstable signal. In the SLC linac, where the beam sizes are about $100 \mu \mathrm{m}$, a beam intensity of about $2.5 \times 10^{10}$ is required. This effect appears to be field emission induced by the field of the beam which peaks at about $20 \mathrm{~V} / \AA$.

Because of these problems, tests were made to determine if a significant signal was present at $90^{\circ}$ to the beam direction, directly opposite the wire support card. A strong, very low energy electron signal was seen in a bare photomultiplier (PMT) placed about $30 \mathrm{~cm}$ from the wirc. $A$ thin window is required so that this scattered radiation is not absorbed by the vacuum chamber wall. Substantial shiclding ( \pm 50 radiation lengths) is required in some locations to protect the PMTs from background generated by upstream beam losses. In regions where no collimators follow the scanners, small angle scattcring monitors have oeen placed about $10 \mathrm{~m}$ downstrcam to use for comparison with the PMT.

The detector linearity must be better than a few percent. A moderate gain, excellent linearity tube was chosen. In order to cross check PMT performance small rast ion chambers were built and installed downstream of some scanncrs ${ }^{6}$ The lincarity of the $A D C$ is also very important.

\section{PERFORMANCE AND CONCLUSIONS}

Performance tests have focused on understanding systematic errors. These tests fall into two broad catcgories: 1) tests made by varying beam size and/or intensity and 2) tesis made with different detectors sensing scatured radiation from a single 


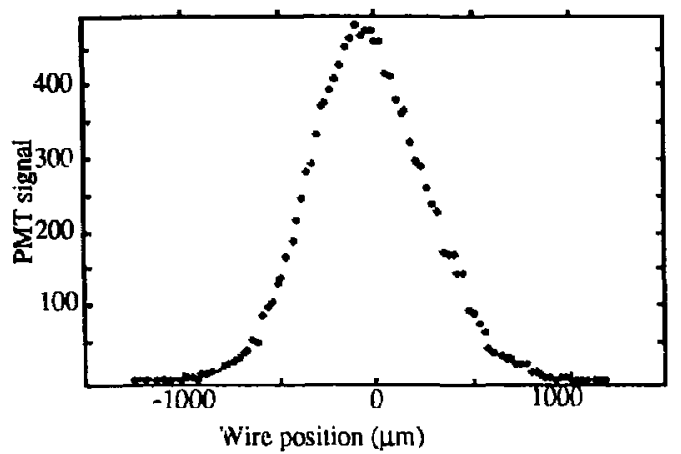

Figure 2: A typical single wire scan. The data are fil with a gaussian with an oflset.

wire. Figure 3 shows the beam emittanc's measured using quadrupole scans ${ }^{7}$ on threc different scainers and multiwirc scans at $1 \mathrm{GeV}$ and $4.5 \times 10^{10}$ e /puise, near the $3 L C$ nominal operating intensity. This is a good test of saturition effects since the beam sizes and signal strengths vary considerably over the scan range and from scarner to scanner. These tests were done using the downstream fast ion chamber.

The SLC wire scanners provide bean emitlance dr.la that is reliable enough to have already yielded ne' insights into the performance of the SLC. By late 1991, 32 scanners will be in use (figure 4). Future linear colliders will have a tighter emittance budget and will require improved resolution

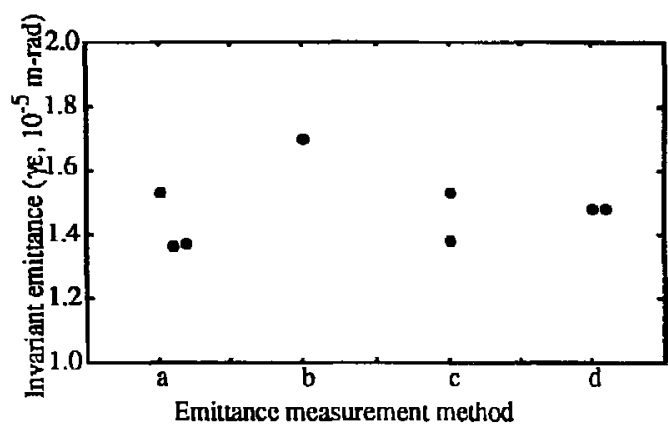

Figure 3: Comparison of emitlance measurements made with: multi wire $(a)$ and quadrupole scans $(b-a)$ using different quadrupole magnet / wire scanner combinations. The results are in good agreement.

scanners. Piezo-electric motors, with their very small step size and ultra-high vacuum compatibility, may prove to be an appropriate technology for future wire scanners. Two such scanners are installed for use at the SLC P.

\section{ACKNOWLEDGEMENTS}

We would like to acknowledge the efforts of the linac group for help in commissioning the scanners, the mechanical design and engineering group for mechanical design, $A$. Tilghman for controls, and C. Field, K. Bouldin and C. Young for PMT testing and data analysis.

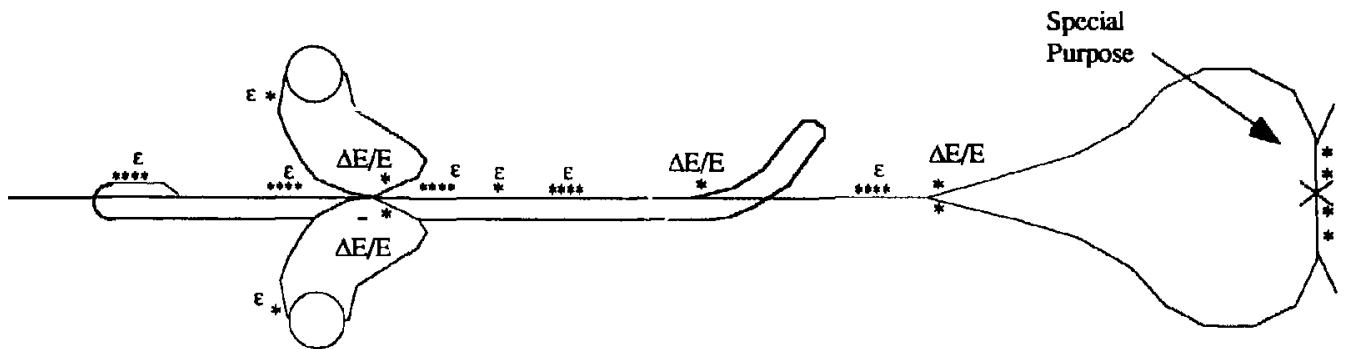

Figure 4: SLC schematic showing the locations of wire scanners. Wire scanners are used for emittance $(E)$, energy spread $(\Delta E / E)$ and special purpose functions in the final focus.

\footnotetext{
' R. Jung and RJ. Colchester, 'Development of Beam Profile and Fast Position Monitors for the LEP Injector Linacs', IEEE Trans. Nucl. Sci. NS32-5:1917, 1985.

2 R.I. Culler ct. al., Performance of Wire Scanner Bcam Profile Monitors to Determine the Emittance and Position of High Power CW Electron Beams of the NBS-Los Alamos Racetrack Microtron', Proccedings of the 1987 IEEE Particle Accelerator Conference, p. 625, 1987.

3 K.D. Jacobs et.al., 'The Beam Profile Measurement System at the Bates Linac', Proccedings of the 1989 lEEE Particle Acceicrator Conferencc, p. 1523, 1989.
}

${ }^{4}$ L. Sanchez-Chopitea et. al., 'Correlation Plot Facility in the SLC Control System', proceedings of this conference.

5 R. Fulton et. al., 'A High Resolution Wire Scanner for Micron Size Profilc Measurements at the SLC', Nucl. Instr. Meth. A274:37, 1989.

${ }^{6} \mathrm{D}$. McCormick, Fast Ion Chambers for SLC'. proceedings of this conference.

${ }^{7}$ M.C. Ross et. al.,'Automated Emittance Measurements in the SLC', Proceedings of the 1987 IEEE Particle Accelerator Conference. p. 725, 1987. 